\title{
TEMA IV
}

\section{PESQUISAS EM ENFERMAGEM - FADIGA E ASPECTOS ERGONOOMICOS NO TRABALHO DE ENFERMAGEM*}

\author{
Maria Yvone Chaves Mauro \\ Delzuite de Souza Cordeiro \\ Kuniko Yanaguisawa \\ Joana Eurides da Conceição
}

**

RBEn/01

MAURO, M.Y.C. e colaboradores - Fadiga e Aspectos Ergonômicos no Trabalho de Enfermagem. Rev. Bras. Enf.; DF, 29 : 7-18, 1976.

\section{INTRODUÇÃO}

\section{Apresentação}

$\mathrm{Na}$ impossibilidade de se oferecer com a presente pesquisa, uma panorâmica geral do problema, espera-se que os seus resultados venham despertar o interesse de outros profissionais de enfermagem para futuros trabalhos acerca da problemática.

f de modo auspicioso que se relata a participação de organizaçōes internacionais, como a Organização Internacional do Trabalho - OIT - e a Organização Mundial de Saúde - OMS, sobre o estudo dos Problemas de trabalho e Condiçōes de Vida do Pessoal de Enfermagem. Pouco ou nada se conhece a respeito dessa problamática e da importância dos estudos que essas organiza- çōes vêm realizando, pois, as leis, a História de Enfermagem, e outras publicaçōes feitas pelas Associaçōes e Escolas em nosso meio, enfim, toda a literatura disponível e as memórias relatadas, não nos esclarecem sobre essa problemática, nem sobre o desenvolvimento desses estudos.

Mais um desafio é lançado para o pessoal de enfermagem através da nova especialização em Enfermagem do Trabalho; mais esforço é solicitado, mais coragem é exigida para que se possa acompanhar o Brasil na sua nova condição de "país emergente" em pleno desenvolvimento econômico, tecnológico e social.

- Trabalho premiado com a MEDALHA EDITH DE MAGALHAES FraENREL Ano 1976.

* Enfermeiras do Departamento Geral de Saúde Pública do Munićpín do Rio de Janeiro. 
MAURO, M.Y.C. e colaboradores - Fadiga e Aspectos Ergonómicos no Trabalho de Enfermagem. Rev. Bras. Enf.; DF, 29 : 7-18, 1976.

As autoras, após o Curso de Enfermagem do Trabalho, pretenderam estudar as condiçōes de trabalho do operário, mas se defrontaram com perguntas sem respostas sobre a própria profissão de enfermagem. Isso estimulou as mesmas, a voltarem o se unteresse para o estudo das condições de trabalho do seu grupo profissional.

A motivação alcançada foi ainda maior quando através do levantamento bibliográfico encontrou-se nas publicaçōes da OIT, referência sobre uma recomendação publicada antes da segunda Guerra Mundial, que exigia a limitação de horas de trabalho no hospital, além de outras exigências.

Segundo O'LEARY (1958), nos primórdios da Enfermagem, essa profissão era exercida como preceito religioso de serviço ao próximo. Hoje muitos requisitos são exigidos do pessoal de enfermagem como curso de Graduação, Especializaçōes e Pós-Graduaçōes. Trata-se de uma profissão árdua, que requer muita saúde física e mental, mas, raramente, se tem proporcionado aos que trabalham nesse campo, a proteção social que se considera geralmente normal em casos semelhantes a outros profissionais.

Todos os profissionais da área de saúde, conhecem pelo menos teoricamente, os efeitos que as atividades em certos setores de trabalho, exercem sobre o pessoal de enfermagem, tais como: Unidade de Tratamento Intensivo, Unidade de Emergência, Unidade Operacional - Centro-Cirúrgico e Centro de Material, Serviço Noturno, Salas de Diálise, etc. Contudo, a proteção social a que esses têm direito, são idênticas às daqueles que exercem atividades menos estafantes e de menor envolvimento emocional. Por outro lado outros profissionais como, os técnicos de laboratório, técnicos de RX e pessoal que opera em ambientes insalubres, têm direito 8 receber vantagens sociais diferenciadas
Os fatores acima mencionados levam a enfermagem à uma tendência de penúria numérica crônica, gerada pela importância espetacular da demanda latente dos serviços de enfermagem, se agravando pela falta de atrativo dessa profissão, além de outros fatores também conhecidos, que são fontes de insatisfação cotidiana, porque influem profundamente nas condiçōes de trabalho do pessoal de enfermagem. Exemplos:

- contratação indiscriminada de pessoal inadequadamente qualificado para as funçōes de enfermagem, criando categorias especiais de pessoal, desnecessárias na enfermagem;

- utilização de estudantes de enfermagem como pessoal de apoio sem remuneração, em postos que deveriam ser ocupados por profissionais;

- utilização insuficiente das qualificaçōes do pessoal profissional;

- fadiga nervosa acumulada;

- dificuldade de se oferecer repouso adequado para recuperação de energias e lazer;

- dificuldade na formação de equipes harmoniosas, o que impede a organização racional do trabalho e a execução qualificada dos serviços prestados;

- problemas relativos à delimitação de atribuiçōes e funçōes, tornando tensas as relaçōes no trabalho;

- remuneração não condizente com o gráu de responsabilidade imposta e assumida;

- falta de prestígio da profissão, desviando para outras profissōes candidatas mais qualificadas.

Por esses e outros fatores conclui-se que a situação moral e social do profissional de enfermagem está clamando por sérios estudos e providências. Como conseqüência, encontra-se 0 pessoal de enfermagem descontente e sempre tenso para defender seus interesses profissio- 
MAURO, M.Y.C. e colaboradores - Fadiga e Aspectos Ergonómicos no Trabalho de Bnfermagem. Rev. Bras. Enf.; DF, 29 : 7-18, 1976.

nais, éticos e econômicos. Segundo a OIT-OMS (1976): se reconhece que no seu conjunto o pessoal de enfermagem se acha freqüentemente em uma situação, que não corresponde à importância de suas funçōes, nem ao peso de suas responsabilidades, na Elevação do Nível Geral de Saúde e Bem-Estar no Mundo.

São conhecidos os esforços que vêm sendo feitos a nível nacional com a ajuda da OMS, para melhorar e elevar os níveis de saúde. Certamente isso trará grande influência para a profissão, gerando oportunidades para que os profissionais de enfermagem possam fazer car. reira, ter maior satisfação no trabalho, conseguir maiores recursos e possibilidades de melhor atendimento ao público. animador também, saber-se que na reunião conjunto OIT-OMS de 1976, o 7.0 assunto que foi discutido versou sobre o Emprego e Condiçōes de Trabalho e de Vida do Pessoal de Enfermagem.

O abandono ou a troca de emprego por muitos profissionais em busca de melhores condiçōes e melhor remuneração, levam a enfermagem, a uma situação que se considera grave, tanto em qualidade como em quantidade de pessoal, acreditando-se que essa situação não ajudará a América Latina, a atingir o percentual mínimo preconizado pela OMS como meta para 1980 - 4,5 de enfermeiras e técnicos de enfermagem por 10.000 habitantes. Especificamente para o Brasil, segundo o BOLETIM INFORMATIVO DA ASSOCIAÇAO BRASILEIRA DE ENFERMAGEM (janeiro-1975), para uma população estimada em 125 mihões de habitantes em 1980, são necessárias 56.250 enfermeiras e técnicos de enfermagem e 181.250 auxiliares de enfermagem.

CARVALHO (1975) refere que a "estimativa de pessoal de enfermagem em atividade no Brasi, foi de cerca de 11.000 enfermeiras, 600 técnicos de enfermagem e 28.000 auxiliares de enfermagem".

\section{PROBLEMA E HIPOTESES FORMULADAS}

Origem do Problema e suas Delimitaçōes

Vários fatores condicionaram a atenção do grupo de pesquisadoras que exercendo funçōes administrativas de enfermagem, e já motivadas pelos assuntos relacionados com a proteção do trabalhador, sentiram-se atraídas para estudar as condiçōes de trabalho do pessoal de enfermagem.

Sendo o campo de enfermagem demasiadamente vasto, impossibilitando a realização de uma pesquisa em todas as áreas, a Divisão de Enfermagem do Departamento Geral de Saúde Pública, decidiu restringir a pesquisa, às condiçōes de trabalho do enfermeiro nosCENTROS DE SAUUDE DO MUNICIPIO DO RIO DE JANEIRO, relacionando-a à fadiga.

Considera-se este trabalho, o inicio de uma série de pesquisas sobre o assunto, o qual poderá ser continuado por esta Divisão, ou por outros profissionais interessados na melhoria dos padrōes de trabalho do pessoal de enfermagem.

Outro fator importante na escolha do campo a pesquisar, foi a facilidade de acesso ao mesmo.

Dado a identificação com os problenas acima citados, formulou-se as seguintes hipóteses:

- Os enfermeiros dos Serviços de Saúde Pública no Município do Rio de Janeiro, normalmente se fatigam no trabalho.

- A presença dessa fadiga resulta da não observância dos princípios ergonômicos aplicáveis às tarefas de enfermagem. 
MAURO, M.Y.C. e colaboradores - Fadiga e Aspectos Ergonômicos no Trabalho de Enfermagem. Rev. Bras. Enf.; DF, 29 : 7-18, 1976.

\section{Objetivos da Pesquisa}

- detectar a existência de fadiga entre os enfermeiros;

- identificar alguns fatores no trabalho do enfermeiro que levam à fadiga;

- identificar alguns procedimentos inadequados à antropometria dinâmica;

- relacionar os recursos tecnológicos utilizados no momento pelos enfermeiros para a prevenção da fadiga.

\section{REVISAO DA LITERATURA}

O grande progresso científico e tecnológico que caracteriza o mundo atual, tem trazido à raça humana condiçōes de conforto e bem-estar jamais sonhados pelos nossos antepassados não muito distantes. As coisas se passam como definiu MILLER-BURT (1973) - "basta apertar um botão e tudo aparece pronto".

Em compensação, grandes foram também os danos que o progresso trouxe à saúde daquele que é o obreiro desse conforto material, o homem que trabalha, diminuindo-lhe a capacidade física como já foi demonstrado por diversos estudiosos da fisiologia do trabalho.

Como conseqüência do progresso industrial, criaram-se novas substâncias, muitas delas tóxicas, que no seu preparo, produção e utilização, dão oportunidade para o surgimento de doenças profissionais, agravando-se por vezes às condiçōes de ambiente desfavoráveis de umidade, temperatura, intensidade de ruídos e vibraçōes, iluminação inadequada ou insuficiente, comprometendo tanto a saúde como o bem-estar social do homem, e conseqüentemente da própria comunidade.

Dentre os problemas que mais afetam o trabalhador, ressalta-se em especial a FADIGA, que não sendo uma enfermidade, causa no indivíduo mal-estar com alteraçōes em seu estado psicossomático, conseqüentemente ocasionando-lhe insegurança, irritabilidade, agressividade, intolerância a ruídos, dificuldades de concentração, propensão à enfermidades com maior freqüência às doenças infecciosas e maior exposição à riscos de acidentes.

Como foi citado por BARRETO (1951), a fadiga industrial interfere na produtividade do operário, baixando-lhe o rendimento e provocando acidentes. um processo complexo que apresenta múltiplos aspectos e é estimulado por várias causas. Não pode ser encarado apenas como resultante do esforço físico e mental: influência das condiçōes do ambiente e fatores psicológicos.

t inegável que interferem na fadiga, além desses fatores inerentes ao regim. e condiçōes de trabalho: o trabalho prolongado, o trabalho pesado demandando grande esforço muscular, vias de acesso mal construídas, mal conservadas e defeituosas; também influenciam no aparecimento da fadiga fatores estranhos ao trabalho profissional como: ocupaçōes externas, alimentação inadequada, abuso de bebidas alcoólicas, desregramento de vida, habitação inadequada e distante do local de trabalho, forçando a viagens fatigantes, etc...

A fadiga depende também das condiçōes individuais: hábito de trabalho $\mathrm{e}$ adaptação às exigências pessoais; constituição e temperamento variável influenciando na eliminação de fatores emocionais, que pertubam muitas vezes a eficiência do trabalho; stress emocional de origem estranha à natureza do seu trabalho; inadaptação afetiva ao tipo de trabalho que desenvolve, etc...

Finalmente, a fadiga traduz-se sobretudo por uma baixa na perícia com que o indivíduo executa seu trabalho, tornando-o comparável muitas vezes a um principiante. Nas tarefas finas e delicadas, retrata-se pela diminuição da 
MAURO, M.Y.C. e colaboradores - Fadiga e Aspectos Ergonômicos no Trabalho de Enfermagem. Rev. Bras. Enf.; DF, 29 : 7-18, 1976.

coordenação dos movimentos e falta de precisão na sua execução.

Considerando a sintomatologia citada por MILLER-BURT (1973) e HENRIITIRO (1973) relacionam-se entre outras as seguintes causas que mais freqüentemente levam à fadiga:

- posição estática;

- repouso inadequado;

- iluminação e ventilação deficientes;

- ruido, calor e umidade inadequados;

- falta de racionalização no trabalho noturno;

- má alimentação;

- falta de conforto no ambiente de trabalho;

- monotonia ocasionada pela repetição das mesmas operaçōes;

- tarefas desagradáveis;

- ambiente insalubre;

- trabalho sem ritmo;

- uso de bebidas alcoólicas e tóxicas;

- fumo excessivo;

- falta de adaptação ao trabalho;

- ausência de lazer;

- excesso de horas extraordinárias;

- horas de sono insuficientes;

- problemas emocionais ou transtornos psicológicos.

Estas causas podem levar à uma fadiga aguda ou crônica.

Segundo MILLER-BURT (1973), até o presente momento, não são conhecidas todas as causas da fadiga, todavia, qualquer que seja sua origem, a evidência da mesma, já é um alerta para a necessidade do repouso e do lazer, intercalados nos períodos normais do trabalho.

A enfermagem, fazendo parte do contexto das ocupaçōes em geral, e das Profissōes da Saúde em particular, encaixase nessa problemática relacionada às condiçōes pessoais e de trabalho, objetivando a maior produtividade sem pre- juízo das faculdades físicas e mentais do trabalhador.

Conforme referência do INFORME VII (1) OIT-OMS (1973) a ocupação de enfermagem, não fugindo às exigências da necessidade de conforto e segurança profissional, pela natureza do seu trabalho, quer em hospital, indústria ou nas Unidades de Saúde Pública, expōe o seu pessoal a múltiplos riscos.

E uma das profissōes que contribuem para preservar a vida e a saúde do homem, mas ainda não conseguiu resolver os problemas relativos à sua própria proteção, estando sujeita à excessiva carga de trabalho e fadiga mais ou menos crônica.

A Conferência Internacional do Trabalho da OIT, em 1944, dedicou uma sessão para o estudo do "Empleo y Condiciones de Trabajo y de Vida del Personal de Enfermería" reconhecendo a necessidade de oferecer a estes, condiçōes de trabalho e situação jurídica satisfatória para garantir a qualidade da assistência no setor saúde.

Igualmente a OMS, na sua $1 .^{\text {a }}$ reuniāo, em 1948, estudou o assunto e considerou a enfermagem "como um elemento essencial aos programas de saúde, organizados para o tratamento dos doentes, a prevenção das doenças, a promoção e preservação da saúde".

Várias reuniōes foram realizadas pela OIT, até que em 1960, com a colaboração da OMS, publicaram um estudo sobre "Empleo y Condociones de Trabajo del Personal de Enfermería". (5) As conclusōes desse estudo sobre o pessoal de enfermagem e demais membros da equipe de saúde, foram propostas em 1973, para servir de guia preliminar de estudo aos governos e empregadores. A comissão encaminhou essa resolução aos respectivos Diretores Gerais da OIT e OMS, a fim de estudarem e convocarem posteriormente os "experts" para examinarem os problemas e apresentarem pro- 
MAURO, M.Y.C. e colaboradores - Fadiga e Aspectos Ergon6micos no Trabalho de Enfermagem. Rev. Bras. Enf.; DF, 29 : 7-18, 1976.

postas de ação, por parte de ambas as organizaçōes. Também recomendou que se tomem medidas a nível regional, principalmente nos países em via de desenvolvimento.

Após esta fase preliminar foi elaborado um Instrumento Internacional com a recomendação de inscrever a questão do "Empleo y Condiciones de Trabajo y de Vida del Personal de Enfermería", na ordem do dia como $7.0^{\circ}$ assunto da 61. ${ }^{2}$ reunião da Conferência Internacional do Trabalho, realizada em 1976.

Entre as conclusōes propostas pelos 53 países, segundo o Informe VII (2), OIT-OMS (1976), destacam-se:

- a adoção de um Instrumento Internacional que proporcione emprego e condiçōes de trabalho adequado ao pessoal de enfermagem;

- o desenvolvimento de um sistema do pessoal de enfermagem;

- medidas práticas concedendo autoridade suficiente para alcançar os objetivos da política nacional em matéria de serviços e de pessoal de enfermagem;

- planejamento baseado em informacōes precisas;

- normas técnicas adequadas às condiçōes nacionais;

- estudo a nível nacional das funçōes de pessoal de enfermagem;

- facilidade de recursos técnicos e materiais apropriados;

- enfoque especial à formação básica da enfermeira e pessoal auxiliar;

- legislação relativa ao exercício profissional;

- adoção de medidas que garantam perspectivas de carreira;

- possibilidades de estruturação de quadros de remuneração condigna às responsabilidades crescentes;

- facilidades para desenvolvimento de programas de educação permanente em serviço;
- adaptação das disposiçōes legislativas em matéria de higiene e segurança do tabalho às caracteristicas do trabalho de enfermagem e do meio em que se realiza.

Das conclusōes acima uma sobressai pelo valor das medidas a serem tomadas em relação à proteção da saúde que se aplica ao pessoal de enfermagem.

O Estado, as Organizaçōes representativas da classe, os empregadores e os próprios enfermeiros, devem estar atentos no sentido de adequar as medidas de proteção da saúde, ao pessoal de enfermagem, visando reduzir ou eliminar os riscos, oferecendo conforto e segurança a esses profissionais.

\section{METODOLOGIA DA PESQUISA}

\section{Critérios para Seleção de Amostragem}

Dentre os 23 Centros Municipais de Saúde do Rio de Janeiro, com uma população de 229 enfermeiros, foram selecionados 15 Centros de Saúde, constituindo uma amostragem de 150 enfermeiros, o que resultou, ao acaso, serem todos os elementos do sexo feminino.

O critério de seleção adotado para amostragem, foi definido pelas características da clientela assistida e localização dos Centros de Saúde em zona rural e urbana, nos quais foram coletados os dados.

A pesquisa limitou-se apenas à categoria profissional de enfermeiro, sendo estes regidos pelo Estatuto dos Funcionários Públicos do Município ou pela Consolidação das Leis Trabalhistas, cuja jornada de trabalho é de 33 horas semanais.

Esses profissionais como em qualquer área da Enfermagem, executam as quatro atividades básicas: Administrativa, Técnica, Ensino e Educação e de Pesquisa, destacando-se algumas tarefas 
MAURO, M.Y.C. e colaboradores - Fadiga e Aspectos Ergonómicos no Trabalho de Enfermagem. Rev. Bras. Enf.; DF, 29 : 7-18, 1976.

especificas de Saúde Pública, por exemplo:

- Supervisiona a execução de todas as tarefas desempenhadas pelo pessoal auxillar no serviço interno e externo.

- Participa do levantamento dos recursos e das necessidades da comunidade.

- Promove e mantém entrosamento com as demais instituiçōes da área.

- Promove a educação permanente em serviço.

- Promove e executa os programas de educação para a saúde pública.

- Participa dos programas de atualização em saúde, para professores, pais e alunos das escolas de $10^{\circ}$ e $2 .^{\circ}$ gráus.

- Realiza consulta de enfermagem com noivos, gestantes, crianças $\left(\begin{array}{lll}0 & \text { a }\end{array}\right.$ anos) escolares e outros.

- Dá cumprimento às prescriçōes médicas e faz orientação pós-clínica.

- Faz entrevista inicial com os pacientes de tuberculose, hanseniase, doenças venéreas e outras.

- Participa do programa e execução do BCG intradérmico na população escolar de sua área.

- Engaja-se em todos os programas e campanhas de vacinação a nível Nacional, Estadual e Municipal.

- Faz vacinação em crianças e adultos no serviço interno, e, no externo, em áreas urbanas e rurais, inclusive morros, favelas e cortiços.

- Realiza Visita Domiciliária para rasteamento de foco e controle de Doenças Transmissiveis.

- Faz Visita Domiciliária para prestar cuidados de enfermagem à gestante, recém-nascidos, puérpera e crianças, quando necessário.

\section{Instrumentos Utilizados}

$O$ instrumento utilizado para a coleta de dados foi o questionário visando de- tectar a fadiga no trabalho. Primeiramente fol realizado um teste elementar com algumas enfermeiras. Visto a exiqüibilidade do questionário, foram posteriormente enviados 150 questionários aos Centros de Saúde, havendo um retorno de 144, com os quais foi desenvolvido o trabalho.

O parâmetro adotado para verificar a ocorrência de fadiga entre as enfermelras, foi o reconhecimento das causas que mais freqüentemente conduzem à fadiga já mencionadas na revisão da literatura, que servirão para comparar as informaçōes coletadas dos questionários.

O processamento dos dados foi feito manualmente.

\section{Definição de Termos}

ANTROPOMETRIA DINAMICA - é o estudo das medidas funcionais, isto é, medida das pessoas enquanto executam alguma função. Sua aplicação contribui para adaptar o trabalho ao homem, dando-lhe conforto, segurança e eficiência.

ANTROPOMETRIA ESTATICA - está relacionada com a medida das dimensōes físicas de corpo parado. Seu estudo contribue para o planejamento de assuntos, mesas, passagens, equipamentos pessoais, etc....

ASPECTOS ERGONOMICOS - medidas e orientaçōes ditadas pela ERGONOMIA, para aumentar a eficiência no trabalho, reduzir os custos, proporcionar conforto ao trabalhador e contribuir para o bem-estar humano.

ERGONOMIA - (vem de grego ERGON = trabalho e NOMOS = lei) é o estudo da adaptação do trabalho ao homem. O seu objetivo central é o ser humano: Várias disciplinas científicas e tecnológicas formam 0 arcabouço da ergonômia. 
MAURO, M.Y.C. e colaboradores - Fadiga e Aspectos Ergonômicos no Trabalho de Enfermagem. Rev. Bras. Enf.; DF, 29 : 7-18, 1976.

ESPAÇO DE TRABALHO - é um espaço imaginário, necessário para o organismo realizar os movimentos requeridos por um trabalho.

EDUCAÇAO PERMANENTE EM SERVIÇO - é um conjunto de atividades planejadas e organizadas para grupos de profissionais e outros servidores e tem por meta o crescimento do pessoal para melhor rendimento do bom final de qualquer empresa.

LAZER - é a utilização das horas de folga para repouso, distraçōes, exercícios e execuçōes de atividades que trazem prazer ao indivíduo. A finalidade é repor as energias gastas no trabalho.

SERVIÇO EXTERNO - são atividades desenvolvidas fora da Unidade de Saúde, envolvendo a comunidade, por exemplo:

Visita domiciliária, visita a hospital, visita a recursos da comunidade, trabalho com grupos em escolas, favelas, associaçōes, etc. ...

SERVIÇO INTERNO - em Unidade de Saúde, são atividades desenvolvidas dentro dos limites da unidade, envolvendo ou não o público, por exemplo: entrevista, consulta de enfermagem, vacinação, preparo do cliente, etc....

\section{ANALISE E DISCUSSAO DOS RESULTADOS}

\section{Análise}

As tabelas foram montadas e baseadas nas informaçōes contidas nos questionários, sendo utilizado para análise o teste Quiquadrado e percentuais.

Na tabela I, "Avaliação de fadiga segundo a percepção dos sintomas referidos pelas enfermeiras...", verifica-se a hipótese de independência entre sintomas de fadiga e percepção dos sintomas.

Na tabela II, "Avaliação das condiçōes de trabalho que levam a fadiga segundo as informaçōes referidas pelas enfermeiras....", verifica-se a hipótese de inde- pendência entre condiçōes que levam a fadiga e sintomas apresentados pelas enfermeiras.

Na tabela III, "Avaliação dos aspectos ergonômicos segundo as condiçōes do trabalho referidos pelas enfermeiras..." verifica-se a hipótese de independência entre condiçōes de trabalho e avaliação dos aspectos ergonômicos.

Na tabela IV, "Avaliação da Prevenção da fadiga segundo fatores que impedem o aparecimento da mesma, expressados pelas enfermeiras...", verifica-se a hipótese de independência entre os fatores que impedem o apararecimento da fadiga e sua prevenção.

Na tabela V, "Especificação e avaliação das pausas segundo tipos e propósitos visados pelas enfermeiras...", verifica-se a hipótese de independência entre os tipos de pausa e intervalos com propósito de descansar.

A tabela VI, "Especificação das atividades de enfermagem segundo frequência e condiçōes de trabalho realizado pelas enfermeiras...", analizado em termos de percentuais, conclui-se que o total de 144 enfermeiras, 84\% lidam diretamente com o público, e das 134 que desempenham atividades de serviço interno também $84 \%$ trabalham em contato direto com o público.

Na tabela VII, "Avaliação dos tipos de ocupação exercida paralelamente às atividades nos Centros de Saúde, mencionados pelas enfermeiras...", das 144 informantes, $58 \%$ declararam que desempenham paralelamente à função de enfermeira de Saúde Pública, atividades domésticas; e $32 \%$ exercem outros cargos de enfermagem e/ou professora.

Na tabela VIII, "Informaçōes prestadas segundo o tempo de trabalho das enfermeiras na profissão de enfermagem...", das 144 enfermeiras consultadas, $51 \%$ trabalha há mais de 21 anos nesta profissão, e $91 \%$ há mais de 11 anos. 
MAURO, M.Y.C. e colaboradores - Fadiga e Aspectos Ergonômicos no Trabalho de Enfermagem. Rev. Bras. Enf.; DF, 29 : 7-18, 1976.

A taleba IX, "Avaliação do tipo de postura corporal utilizada frequentemente pelas enfermeiras...", indica que $56 \%$ das 144 enfermeiras consultadas trabalham em permanente movimentação.

Na tabela $X$, "Problemática de saúde mais frequente citada pelas enfermeiras...", o percentual calculado de 88 informaçōes (56 enfermeiras não informaram), $21 \%$ apresenta problema de coluna.

\section{Discussão}

Conclue-se da análise das tabelas I, II, III, IV e V, que as enfermeiras apresentam sintomas característicos de fadiga. Ressaltam-se dois aspectos que merecem estudo acurado:

- fatores pessoais ligados a inobservância dos aspectos ergonômicos;

- fatores ambientais, ligados às condiçōes inadequadas em que desempenham suas tarefas.

Na tabela VI, vê-se que o tipo de atividade citada (diretamente com 0 público) expōe o profisional mais frequentemente a emoçōes intensas, porque atende a uma população em sua maioria de nível socio-econômico mais baixo, por vezes hostil e agressiva, podendo levá-la a uma instabilidade emocional.

Na tabela VII, vê-se que $91 \%$ das enfermeiras possuem duas ou três atividades árduas (enfermagem, ensino e doméstica), trabalhos que demandam um maior consumo de energia física, mental e emocional. Somente isto daria margem para um estudo mais profundo sobre 0 problema que envolve toda a classe.

Observando-se a tabela VIII, (51\% de profissionais com mais de 21 anos de trabalho) e partindo-se do pressuposto de que as enfermeiras informantes iniciaram a carreira aos 20 anos, presume-se que estariam hoje com a idade de 41 anos, sendo esse, outro fator que predis- pōe com mais facilidade à fadiga. Observa-se também que não houve admissão de enfermeiras/os nos ultimos anos (3\% de profissionais com menos de 5 anos) ocasionando maior sobrecarga àqueles profissionais, evidenciando-se claramente maior exposição desses elementos à fadiga.

Pela análise da tabela IX, conclue-se a importância cada vez maior que deverá ser dada à antropometria dinâmica (56\% das enfermeiras trabalham em movimentação permanente), que tem sua atenção voltada para as medidas funcionais, isto é, medidas pessoais em rejação a função executada. As características relativas a tais funçōes incluem ângulo, faixa de velocidade e aceleração, padrōes de ritmo e movimentos, além de forças e espaços envolvidos. Conforme fol apontado por DEMPSTER (Ergonomia - 1973), os estudos baseados em medidas dinâmicas contribuem para o conforto, eficiência e segurança nas $\nabla a ́-$ rias fases da vida humana. $O$ oposto leva um maior consumo de energia, com desgastes físicos, e consequentemente maior fadiga, quando não são observados os princípios da ergon6́mia.

Dentre as tabelas que foram analisadas e não incluídas dado a extensão do trabalho, verificou-se que $21 \%$ das enfermeiras exercem atividades no setor de de Vacinaçōes; as enfermeiras săo levadas pela natureza das atividades desenvolvidas neste setor, a uma grande movimentação em ambiente impróprio, extremamente ruidoso (chôro de crianças), agressivo e tenso. Ficam também expostas às doenças (atendem a grande massa populacional) uma vez que nele circulam pessoas supostamente sadias. Outro aspecto a ser ressaltado, é o uso de materiais e equipamentos inadequados, exigindo grande esforço muscular da operadora, associando-se a inobservância dos princípios de manutenção dos aparelhos, além da monotonia pelas ati- 
MAURO, M.Y.C. e colaboradores - Fadiga e Aspectos Ergonomicos no Trabalho de Bnfermagem. Rev. Bras. Ene.; DF, 29 : 7-18, 1976.

vidades repetitivas sem substitulção, principalmente em vacinaçōes de massa.

Observando a tabela $\mathbf{Z}$, verificou-se que $21 \%$ das enfermelras informaram ter problemas de coluna, confirmando a exdsténcia de uma relação entre este problema, e a não apllcação dos procedlmentos adequados à antropometria dinâmica, na execução das atividades de enfermagem.

Apesar de, no ensino da enfermagem ser frequentemente enfatizado a racionallzação do trabalho das enfermeiras, através das recomendaçōes: economla de tempo, de esforço e harmonlzação dos movimentos para maior rendimento do trabalho, verifica-se que as mesmas enfermelras, no desempenho de suas atividades cotidianas, não observam esses conhecimentos; aspecto que se reveste de malor Importâncla para a Ergonómla, quando associado às condiçōes de trabalho Inadequados.

Outro aspecto que merece consideração, é a utillbação Inadequada das horas de lazer pelas enfermelras, veriflcada em tabelas que não foram incluidas neste trabalho, problema este agravado pelas condiçōes amblentals próprlas de srandes centros urbanos.

Os recursos clentíficos e tecnológlcos utilluados atualmente para prevenção da fadiga, estão mencionados indiretamente no contexto; na anallise global das tabelas, ficou demonstrado a pouca utilização desses recursos pelas enfermelras.

\section{RESUMO}

As autoras mostram a importáncia do Curso de "Infermelro do Trabalho" que despertou nas mesmas o interesse pelos estudos de problemas relacionados ao trabalho desse proflssional, para observar e detectar riscos efetivos a que está exposto 0 pessoal de enfermagem no exerciclo de sua profissảo, com a finalldade de prevenir, minimizar ou corrifir os riscos. Enfatizam também a ausência de higiêne e segurança do trabalho nas áreas de atuação da enfermagem. Referem-se à falta de adaptação das disposiçōes legtslativas as características Intrinsecas do trabalho desse profissional, e do melo em que se reallza - Hospltal - Casa de Baúde Particular - Escolas, Industrias e Baúde Pública, onde se encontra uma gama de riscos que clamam por uma sérle de medidas, não só por parte do Governo, como das institulçōes representativas de empregadores, das Institulçōes de enfermagem e das próprias enfermelras/os.

Lembram alnda a Importância do lazer e da higlêne mental à ser observada pelas/os enfermelras/os.

\section{RECOMENDAÇOES}

Difundir entre as/os enfermelras/os, 0 estudo de aspectos ergonómicos e de hlgiêne e segurança do trabalho, visando a própria proteção.

Recomendar as autoridades competentes, sérlo estudo para a adaptação da legislação vigente aos aspectos especiflcos do trabalhos de enfermagem, e ao melo onde ele se desenvolve: Hospltals, Casa de Baúde Particular, Indústrias e Saúde Pública, etc...

\section{CONCLUSOES}

As autoras concluiram que:

- há necessidade dos especlalistas em ergonômla, ampliarem seus estudos para o campo especifico da enfermagem;

- o estudo de alguns aspectos ergonômlcos devem ser difundidos entre as/ os enfermelras/0s, visando entre outros objetivos, a prevenção ou mlnimlzação da fadiga;

- 0 estudo das disposições legislativas sobre hlgiêne e segurnça do trabalho, e 
MAURO, M.Y.C. e colaboradores - Fadiga e Aspectos Ergonómicos no Trabalho de En-

fermagem. Rev. Bras. Enf.; DF, 29 : 7-18, 1976.

a adaptação das suas exigências às características do trabalho de enfermagem, deve constituir a meta do governo, das Instituiçōes representativas dos empregadores, do Conselho Federal de Enfermagem e das próprias enfermeiras/os em particular, que são as/os maiores interessados;
- as enfermeiras/os de modo geral, necessitam utilizar adequadamente suas horas de lazer;

- a falta de higiene mental das enfermeiras/os, pode conduzir a um desequilíbrio emocional em relação a clientela, tornando-a menos sensível aos problemas alheios.

\section{REFERECIA BIBLIOGRAFICA}

1 - BARRETO, JOAO DE BARROS - Compêndio de Higiene, Rio de Janeiro, Editora Guanabara, 1951.

2 - CARVALHO, A. C. - Recursos Humanos em Enfermagem. Revista Brasileira de Enfermagem; Rio de Janeiro, 28 (4): 70-77, Jan. Mar., 1975.

3 - ITIRO, IDA, WIERZBICKI, HENRT. - Ergonomia. São Paulo, Ed. Comunicação - Universidade - Cultura, 167 - 200; 1973.

4 - MULFR, BENJAMTN F., BURT, JOHN J. - Salud Individual y Coletiva; EL HOMBRE Y LA Sociedad Actual. Mexico, Nuiva Ed. Interamericana, 1973.

5 - OIT - Empleo y Condiciones de Trabajo del Personal de Enfermaria -
Ginebra. Imprimeries Populaires 1960.

6 - OIT - Empleo y Condiciones de Trabajo $\boldsymbol{y}$ de Vida del Personal de Enfermeria. Ginebra, Imprenta H. Studer, Informe VII 1: 2, 1976.

7 - OIT. OMS - Reunion Conjunta sôbre Condiciones de Trabajo y de Vido del Personal de Enfermaria - Ginebra, Informe, Nov. 1973.

8 - O'LEARY, AGNES. - Preparação das Enfermeiras, em Matéria de Educa. ção Sanitáría. IN: BOSP. 45 - (2): ago., 1958.

9 - OMS - OPAS - Plan Decenal de 8alud para las Américas. Washington, D. C. EUA, Documento Oficial n:० 118, 1973.

\section{BIBLIOGRAFIA CONSULTADA}

1 - ALVIM, FRMENGARDA F. - A Enfermeira num serviço de Saúde Ocupacional. IN: Revista de Serviço Especial de Saúde Pública. 12 (2): 267-276, 1966.

2 - ARMSTRONG, JR. GEORGE - Manual de Práticos de Fisiologia. México, Ed. Interamericana, 1970.

3 - BLALOCK, H. M. JR. - Introdução à Pesquisa Social - Rio de Janeiro, Editora Zahar, 1976.

4 - Carvalho, A. C. - Apresentação de Trabalho Cientifico. Revista Brasileira de Enfermagem. Rio de Janeiro, 27 (1) : 86-97, Jan., mar., 1974.

5 - CHAVES, MARIO M. - Saúde e Sistemas - Rio de Janeiro - GB., Fundação Getúlio Vargas, 1-20, 1972.

6 - EDHOLM, O. G. - A Biologia do Trabalho. World University I'ibrary. Biblioteca Universitária Inova. Porto - Portugal.
7 - FARIA, HERMFNIO AUGUSTO. - 3 Pesquisas. Rio de Janeiro. G.B. Ed. Fundação Getúlio Vargas, 1964.

8 - FERRAO, Pericles Valdir - O Homem e \& Máquina. IN: Revista Segurança e Prevenção. 1, fev., 1976.

9 - GOODE, WILIAM J., HATT, PAUL K. - Métodos em Pesquisa Social. 4. Edição, São Paulo, Ed. Nacional, 1972.

10 - GARCIA, OTHON M. - Comunicação em Prosa Moderna. Rio de Janeiro. GB, Fundação Getúlio Vargas, 397 - 405, 1973.

11 - HORST, HAEBISCH. - Fisiologia do Trabalho. IN: FUNDACENTRO SAC PAULO, 2: 372-411, mal., 1973.

12 - KAPLAN, JUAN - La Empresa y la Salud de los Trabajadores. Buenos Aires, Ed. El Ateneo, 1972.

13 - KOZIER, DU GAS - Tratado de Enpermeria Pratica. México, Ed. Interamericana, 1974. 
MAURO, M.Y.C. e colaboradores - Fadiga e Aspectos Ergonomlcos no Trabalho de Enfermagem. Rev. Bras. Enf.; DF, 29 : 7-18, 1976.

14 - MACUCH, P. - Os Perigos de um Longo Dia - IN: Revista Saúde do Mundo, ful., ago., 10-13, 1974.

15 - MINIST GRIO DA SAUDE. FSESP Einfermagem, Leglslaçăo e Assuntos Correlatos. 3." ed. Rilo de Janeiro, 1974.

16 - MINISTRRIO DO TRABAIFO E PREVIDENCIA SOCIAI - Trabalho da Mulher. Dep. Nac. e Segurança do Trabalho, 1973.

17 - NOGUEIRA ORACY - Pesquisa Social. Introduçăo às suas Técnicas. Segunda ediça, são Paulo, Ed. Naclonsl, 1969.

18 - NORDMARK, ROWEDER - Principlos Cientificos Aplicados a La Enfermera. Mexico, La Prensa MexiCans, 1972.

19 - OFT - Las Normas Internacionales del Trabajo. Su naturaleza - Su Aplicación - Su eficacia. Imprimeries Populaires, Ginebre, ago., 1969.

20 - OIT - ILAS TRABAJADORAS. La fuerza de Trabajo femenina mundial em 1975 y las perspectivas para el afio $\mathbf{3 0 0 0}$ Impression Weber, Suiza, ago., 1975.

21 - RODRIGUTS, M. L. - Pesquisa da conduta manlfesta de 27 Enfermelras sobre utlllzagåo de Técnico de Enfermagem no Campo de Saúde Pública 25 (4): 145-170, jul., set., 1972.

22 - SALOMON, DECIO VIFIRA - Como Fazer uns Monografla - Belo Ho- rigonte, Instituto de Psicologia da Universidade Católica de Munas Gerais, 1971.

23 - GANTOS, JOSU IGNACIO - Curso de FIglene e Segurança Industrial. Rio de Janelro, Princeps gráfica 1969.

24 - SESC - Treinamento. Documento 18, Rlo de Janeiro, Jan., mar., 1975.

25 - SECRETARIA DE ESTADO, USA A Enfermeira dos Estabelecimentos Industrials e a Operária. Washington. D. C. Publicaçáo TC -298. 1944.

26 - STRYKER, RUTH PERIN - Enfermera de Rehabllitacion - México, Ed. Interamericana, 1964.

27 - UNTVERSMADE FEDERAL DA BAFIA - FUNDACENTRO - Planejamento do Serviço de Enfermagem da Usina Siderúrgica da Bahia S.A. USIBA. Salvador, 1975.

28 - UNTVERSIDADE FEDERAL DA BAFIIA - FUNDACENTRO - Primeiro Curso de Enfermeiras de Trabalho. Apostilas, Salvador, 1975.

29 - WALTER, LEON - Psicologia do Trabalho Industrial - Rio de Janeiro, Ed. Melhoramentos, 1969.

30 - WARAMATSU, CELINA TAMIE Fisiologia do Trabalho. Såo Paulo, Fundacentro, 1973.

31 - II plano Nacional DE DeseinVOLVIMENTO - Rio de Janeiro. GB., Ed. IBGE, 69-73, 131-133, 1974. 
AVALIAÇAO DE FADIGA SEGUNDO A PERCEPÇAOO DOS SINTOMAS REFERIDOS PELAS ENFERMEIRAS DOS CENTROS MUNICIPAIS DE SAÚDE, (C.M.S.), - 1976

\begin{tabular}{l|r|r|r}
\hline \multicolumn{1}{c|}{ Sintomas de Fadiga } & \multicolumn{2}{|c|}{ Percepção dos Sintomas } & Total \\
\cline { 2 - 2 } & Sim & Não & \\
\hline Fácil irritação & 21 & 123 & 144 \\
Irritação constante ao ruído & 51 & 93 & 144 \\
Horas de sono insuficiente & 39 & 105 & 144 \\
Ansiedade permanente & 26 & 118 & 144 \\
Difícil concentração em atividade & 31 & 111 & 144 \\
$\quad$ intelectual & & & \\
\hline TOTAL & 168 & 552 & 720 \\
\hline
\end{tabular}

Fonte: Dados coletados através de questionários dos C.M.S.

$0 \mathrm{X}^{2}=21.949$ que comparado com $0 \mathrm{X}^{2}=9,49$ mostra que há associação cal.

entre sintoma e percepçāo. $0, C 5: 4$

TABELA II

AVALIAÇAO DAS CONDIÇÓES DE TRABALHO QUE LEVAM A FADIGA, SEGUNDO AS INFORMAÇOES REFERIDAS PELAS ENFERMEIRAS DOS CENTROS MUNICIPAIS DE SAÚDE, (C.M.S.). - RJ 1976

\begin{tabular}{l|c|c|c|c}
\hline & \multicolumn{2}{|c|}{$\begin{array}{c}\text { Sintomas apresentados pelas } \\
\text { enfermeiras }\end{array}$} & \multirow{2}{*}{ Total } \\
\cline { 2 - 4 } Condiçōes que levam à fadiga & Sim & Não & $\begin{array}{c}\text { Não infor- } \\
\text { mou * }\end{array}$ & \\
\hline $\begin{array}{l}\text { Trabalhou durante as últimas } \\
\text { férias }\end{array}$ & 18 & 126 & - & 144 \\
$\begin{array}{l}\text { Desinteresse pelo trabalho } \\
\text { TOTAL }\end{array}$ & 6 & 137 & 263 & 144 \\
\hline
\end{tabular}

Fonte: Dados coletados através os questionários dos C.M.S.

* Não consta na análise.

$0 \mathrm{X}^{2}=6.456$ que comparado com o $\mathrm{X}^{2}=3,84$ mostra que há associação cal.

0,05: 1

entre os dois fatores. 
AVALIACGAO DE ALGUNS ASPECTOS ERGONOMICOS, BEGUNDO AS CONDICOES DE TRABALEO, RH'FRIDO8 PELAS ENFHRMTIRAS NOS CENTROS MUNICIPATS DE SAUDE, (C.M.8.). - RJ - 1976

\begin{tabular}{|c|c|c|c|c|}
\hline \multirow{2}{*}{ Condiçōes de Trabalho } & \multicolumn{3}{|c|}{$\begin{array}{c}\text { Avallaçāo dos aspectos } \\
\text { ergonômicos }\end{array}$} & \multirow{2}{*}{ Total } \\
\hline & Sim & Não & $\begin{array}{l}\text { Não Infor- } \\
\text { maram * }\end{array}$ & \\
\hline $\begin{array}{l}\text { Causam mal-estar a presença } \\
\text { de outras pessoas }\end{array}$ & 26 & 116 & 2 & 144 \\
\hline $\begin{array}{l}\text { Ruidos no local de Trabalho } \\
\text { ocasionando desconforto }\end{array}$ & 97 & 44 & 3 & 144 \\
\hline $\begin{array}{l}\text { Temperatura amblental desa- } \\
\text { gradável }\end{array}$ & 76 & 66 & 2 & 144 \\
\hline $\begin{array}{l}\text { numinação Insuficiente no } \\
\text { local de Trabalho }\end{array}$ & 87 & 57 & 一 & 144 \\
\hline $\begin{array}{l}\text { Desconforto causado pela } \\
\text { umidade }\end{array}$ & 61 & 82 & 1 & 144 \\
\hline $\begin{array}{l}\text { Longas distânclas percorridas } \\
\text { pela má locallzação do setor }\end{array}$ & 38 & 102 & 1 & 144 \\
\hline $\begin{array}{l}\text { Esiorço I1sico exigiao no } \\
\text { trabalho }\end{array}$ & 52 & 87 & 5 & 144 \\
\hline
\end{tabular}

Fonte: Dados coletados através os questionários dos C.M.S.

- Não consta na análise.

$0 \mathrm{X}^{2}=112,831$ que comparado com o valor $\mathrm{X}^{2}=12,59$ mostra que hó cal.

0.05: 6

associação entre os fatores. 
TABBRA IV

AVALIAÇAO DA PREVENÇAO DA FADIGA, BEGUNDO FATORES QUE MMPEDEM O APARECDMENTO DA MOSPMA, FXPRESSADOS PELAS ENEHRMPIRAS DOS CENTROS MONICIPAIS DE SAUDE, (C.M.8.). RJ - 1976

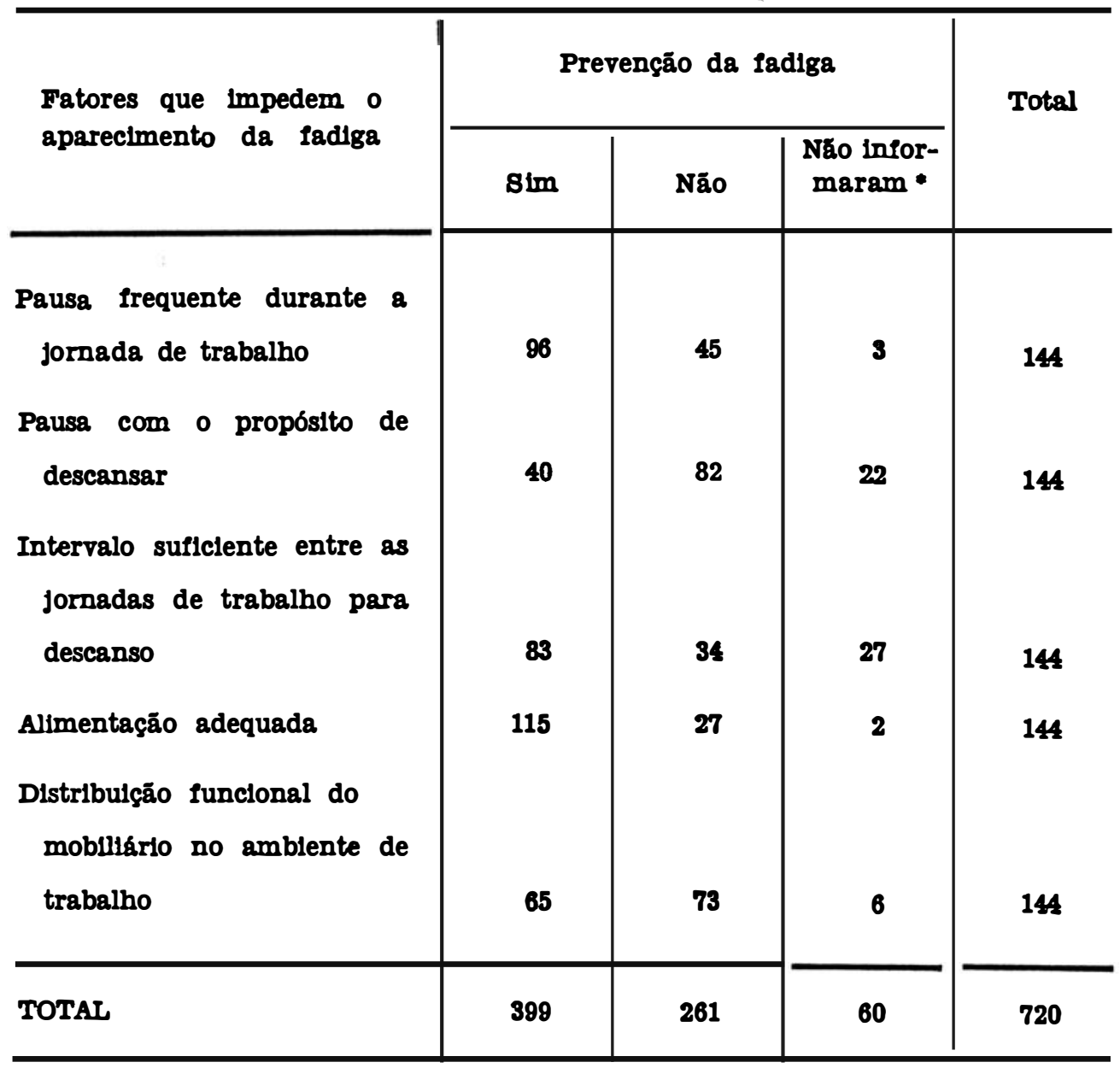

Fonte: Dados coletados através os questionários nos C.M.s.

- Não consta na análise.

$0 \mathrm{X}^{2}=83,209$ que comparado com $0 \mathrm{X}^{2}=9,49$ mostra que há a assoclação cal.

entre fator e prevenção.

$0,05: 4$ 


\section{TABELA V}

ESPECIFICAÇAO E AVALIAÇAO DAS PAUSAS, SEGUNDO TIPOS E PROPÓSITOS VISADOS PELAS ENFERMEIRAS, NOS CENTROS MUNICIPAIS DE SAUDE,

$$
\text { (C.M.S.). - RJ - } 1976
$$

\begin{tabular}{|c|c|c|c|c|}
\hline \multirow{2}{*}{ Tipos de Pausa } & \multicolumn{3}{|c|}{$\begin{array}{c}\text { Intervalos com o propósito de } \\
\text { descansar }\end{array}$} & \multirow{2}{*}{ Total } \\
\hline & Sim & Não & $\begin{array}{l}\text { Não infor- } \\
\text { maram }\end{array}$ & \\
\hline Tomar café & 39 & 26 & 5 & 70 \\
\hline Uso de "Toalete" & 7 & 51 & 4 & 62 \\
\hline Sem informação * & 6 & 6 & 一 & 12 \\
\hline TOTAL & 52 & 83 & 9 & 144 \\
\hline
\end{tabular}

Fonte: Dados coletados através os questionários nos C.M.S.

$0 \mathrm{X}^{2}=30,007$ que comparado com $\circ \mathrm{X}^{2}=3,84$ mostra que há associação cal.

entre os dois fatores.

0,05: 1

- Não consta na análise.

TABELA VI

ESPECIFICACAO DAS ATIVIDADES DE ENFERMAGEM SEGUNDO FREQUENCIA E CONDIÇAO DE TRABALHO, REALIZADO PELAS FNFERMISIRAS NOS CENTROS MUNICIPAIS DE SAƯDE (C.M.S.). — RJ - 1976

\begin{tabular}{l|c|c|c}
\hline \multirow{2}{*}{$\begin{array}{l}\text { Atividade de Enfermagem } \\
\text { mais frequente }\end{array}$} & \multicolumn{2}{|c|}{ Condição de Trabalho } & Total \\
\cline { 2 - 4 } & $\begin{array}{c}\text { Direamente } \\
\text { c/o Público }\end{array}$ & $\begin{array}{c}\text { Indiretamente } \\
\text { c/o Público }\end{array}$ & 134 \\
\hline Serviço Interno & 112 & 22 & 10 \\
Serviço Externo & 9 & 1 & 144 \\
\hline TOTAL & 121 & 23 & 134 \\
\hline
\end{tabular}

Fonte: Dados coletados através os questionários nos C.M.S. 
AVALIAÇAO DOS TIPOS DE OCUPAÇAO EXERCDDA PARALGTAMENTE AS ATIVIDADES NOS CENTROS MUNICIPAIS DE SAUDE R. J. MENCIONADAS PELAS ENFERMEIRAS. - 1976.

\begin{tabular}{l|c|c|c}
\hline \multicolumn{1}{c|}{ Tipos de Ocupação } & $\begin{array}{c}\text { Outras funçōes } \\
\text { exercidas para- } \\
\text { lelamente }\end{array}$ & $\%$ & $\begin{array}{c}\text { F. } \\
\text { ac. \% }\end{array}$ \\
\hline Domésticas & 83 & 58 & 58 \\
Enfermagem & 34 & 24 & 82 \\
Ensino & 13 & 9 & 91 \\
Outras & 12 & 8 & 99 \\
Sem informaçōes & 2 & 1 & 100 \\
\hline
\end{tabular}

Fonte: Dados coletados através os questionários nos C. M. S.

TABELA VIII

INFORMAÇOES PRESTADAS SEGUNDO O TEMPO DE TRABALHO DAS ENFERMEIRAS, NA PROFISSAO DE ENFERMAGEM, NOS CENTROS MUNICIPAIS DE SAÚDE, (C.M.S.). - R.J. - 1976.

\begin{tabular}{l|c|c}
\hline \multicolumn{1}{c|}{ Anos de Trabalho } & N.0 de Enfermeiras & $\%$ \\
\hline Menos de 5 anos & 5 & 3 \\
De 5 a 10 anos & 8 & 6 \\
De 11 a 20 anos & 74 & 40 \\
Mais de 21 anos & 51 \\
\hline TOTAL & 144 & 100 \\
\hline
\end{tabular}

Fonte: Dados coletados através os questionários nos C. M. S. 
AVALIAÇAO DO TIPO DE POSTURA CORPORAL UTILIZADA FREQUENTEMENTE PELAS ENFERMEIRAS NOS CENTROS MUNICIPAIS DE SAÚDE (C. M. S.). - R. J. - 1976.

\begin{tabular}{l|c|c}
\hline \multicolumn{1}{c|}{ Tipo de Postura Corporal } & $\begin{array}{c}\text { Utilização } \\
\text { freqüente }\end{array}$ & $\%$ \\
\hline Em pé & 20 & 14 \\
Sentada & 44 & 30 \\
Em movimento permanente & 80 & 56 \\
\hline TOTAL & 144 & 100 \\
\hline Fonte: Dados coletados através os questionários nos C. M. S.
\end{tabular}

TABELA $\mathbf{X}$

FROBLEMAS DE SAUdE MAIS FREQUENTE, CITADOS PELAS ENFERMEIRAS DOS CENTROS MUNICIPAIS DE SAUDE. (C.M.S.), - R.J. - 1976.

\begin{tabular}{l|c|c}
\hline \multicolumn{1}{c|}{ Queixas } & $\mathrm{X}$ & $\%$ \\
\hline Astenia & 9 & 10 \\
Cefaléia e enxaqueca & 9 & 10 \\
Reumatismo & 10 & 11 \\
Alergia & 8 & 10 \\
Problemas de coluna & 19 & 21 \\
Infeç̧ões & 7 & 8 \\
Hipertensão & 6 & 7 \\
Perturbação digestiva & 5 & 6 \\
Distúrbios nervosos & 9 & 10 \\
Outras & 6 & 7 \\
Sem informação & 56 & - \\
\hline TOTAL & 144 & 100 \\
\hline
\end{tabular}

Fonte: Dados coletados através os questionários dos C. M. S. 